\title{
Negative effects of Aloe vera gel on paracetamol-induced liver injury in rats
}

\author{
Suchittra Samuhasaneeto $^{\mathrm{a}, *}$, Sorrayut Kajornvuthidej ${ }^{\mathrm{b}}$ \\ a School of Medicine, Walailak University, Nakhon Si Thammarat 80161 Thailand \\ b Institute of Pathology, Department of Medical Services, Ministry of Public Health, Bangkok 10400 Thailand \\ *Corresponding author, e-mail: ssuchitt@wu.ac.th \\ Received 26 Feb 2013 \\ Accepted 22 Dec 2013
}

\begin{abstract}
The effect of Aloe vera gel on paracetamol induced liver injury in rats was studied using male Wistar rats divided into four groups. Group 1 (control) received 50\% sucrose orally twice daily for 2 days. Group 2 (paracetamol) received a single dose $(2.5 \mathrm{~g} / \mathrm{kg} \mathrm{BW})$ of paracetamol dissolved in 50\% sucrose. Groups 3 and 4 (A. vera $100 \mathrm{mg}$ and $300 \mathrm{mg}$, respectively) received a single dose $(2.5 \mathrm{~g} / \mathrm{kg} \mathrm{BW})$ of paracetamol dissolved in $50 \%$ sucrose followed by 100 or $300 \mathrm{mg} / \mathrm{kg} \mathrm{BW}$ of $A$. vera gel twice daily for 2 days. Blood was collected to determine alanine aminotransferase (ALT) and aspartate aminotransferase (AST) enzymatic activities. Liver tissue samples were collected for hepatic glutathione, hepatic malondialdehyde (MDA), and histopathology. The results showed that the serum levels of ALT, AST, and hepatic MDA increased significantly in the paracetamol group compared to that of the control group. The liver histopathology in the paracetamol group revealed vacuolization, cell swelling, and mild infiltration of inflammatory cells around the central vein. Necrosis was observed predominantly around the centrilobular and midzonal regions. There were no differences in hepatic glutathione levels between groups and no difference in hepatic MDA levels between the paracetamol group and A. vera gel treated groups. This study concluded that neither 100 nor $300 \mathrm{mg} / \mathrm{kg} \mathrm{BW}$ of $A$. vera protected rats from the liver damage induced by a high dose of paracetamol.
\end{abstract}

KEYWORDS: glutathione, malondialdehyde, serum aminotransferases, centrilobular necrosis, acetaminophen

\section{INTRODUCTION}

Paracetamol is a popular non-prescription analgesic and antipyretic drug. At therapeutic dose, it is believed to be safe but an overdose can cause poisoning and a potentially lethal hepatotoxicity ${ }^{1}$. Paracetamol toxicity is the leading cause of acute liver failure in many countries ${ }^{2-4}$. The toxicity depends on the metabolic activation of paracetamol via cytochrome P450 , which results in the formation of an electrophilic reactive metabolite, $N$-acetyl- $p$-benzoquinone imine $(\mathrm{NAPQI})^{5}$. NAPQI is quickly detoxified by hepatic glutathione to a nontoxic paracetamol-mercaptate compound that is renally excreted ${ }^{1}$. Paracetamol overdose causes glutathione depletion and generation of reactive oxygen species resulting in the metabolite covalently binding to hepatic macromolecules ${ }^{5}$. In addition, oxidative stress, including lipid peroxidation can cause irreversible membrane injury and cell death $^{6-8}$.

Aloe vera, a perennial succulent plant belonging to the Liliaceae family, is widely distributed in tropical areas including Thailand. It has been used worldwide as a traditional medicine for many centuries.
The chemical compositions of $A$. vera leaf include glucomannans, acemannan, minerals, enzymes, inorganic compounds, flavonoid compounds, phenolic compounds, etc ${ }^{9}$. Several studies have demonstrated that $A$. vera extract has therapeutic properties such as anti-inflammatory effects, wound healing, antidiabetic activities and antioxidant effects ${ }^{10-14}$. In addition, some studies show a hepatoprotective effect of $A$. vera. The aqueous extract of $A$. vera has been shown to restore liver enzymes, triglycerides and improve liver histopathology in carbon tetrachloride induced hepatotoxicity ${ }^{14}$. Another study reported that fresh $A$. vera gel reduced serum $\gamma$-glutamyl transferase in petroleum-product induced hepatotoxicity ${ }^{15}$. The aim of this study was to test if $A$. vera has any hepatoprotective effects in rats treated with a high dose of paracetamol.

\section{MATERIALS AND METHODS}

\section{A. vera gel preparation}

A. vera grown in Nakhon $\mathrm{Si}$ Thammarat province, Thailand was used to prepare A. vera gel. A. vera gel was separated from the leaves and homogenized in 
an electric blender. The extract was filtered and then lyophilized using a freeze dryer. A. vera gel powder was stored at $-20^{\circ} \mathrm{C}$ until use.

\section{Total phenolic contents determination}

Total phenolic content in the A. vera gel powder was determined using the Folin-Ciocalteu method ${ }^{16}$ with some modifications, results are expressed as mg gallic acid equivalents per $1 \mathrm{~g}$ of $A$. vera gel powder. One gram of $A$. vera gel powder or standard solution was mixed with $1 \mathrm{ml}$ of $2 \%$ sodium carbonated solution and $50 \mu \mathrm{l}$ of Folin-Ciocalteu reagent. After incubation for $30 \mathrm{~min}$ at room temperature, the absorbance was measured at $750 \mathrm{~nm}$ on a visible spectrophotometer.

\section{Animals}

Male Wistar rats weighing between 220 and $250 \mathrm{~g}$ were purchased from the animal centre, Faculty of Science, Prince of Songkla University. The rats were kept in cages with access to food and water ad libitum in a room with controlled temperature $\left(23 \pm 2^{\circ} \mathrm{C}\right)$ and a 12-h light-dark cycle. The study protocol was approved by the Ethics Committee on Animal Experiment of Walailak University (protocol number 001/2011, approved on 18 April 2011). The rats were fasted for $12 \mathrm{~h}$ before the experiment. The rats were divided into 4 groups of 6 rats each. Group 1 (control) received 50\% sucrose orally twice daily for 2 days. Group 2 (paracetamol) received a single dose $(2.5 \mathrm{~g} / \mathrm{kg} \mathrm{BW})$ of paracetamol dissolved in $50 \%$ sucrose. Groups 3 and 4 (A. vera $100 \mathrm{mg}$ and $300 \mathrm{mg}$, respectively) received a single dose $(2.5 \mathrm{~g} / \mathrm{kg} \mathrm{BW})$ of paracetamol dissolved in 50\% sucrose followed immediately by oral administration of 100 or $300 \mathrm{mg} / \mathrm{kg}$ BW of $A$. vera gel twice daily for 2 days.

The doses of $A$. vera gel in the present study based on the hepatoprotective activity of $A$. vera gel ${ }^{15}$. The $300 \mathrm{mg} / \mathrm{kg} \mathrm{BW}$ of $A$. vera gel exhibited hepatoprotective activity in petroleum products-induced liver injury ${ }^{15}$. Furthermore, the $100 \mathrm{mg} / \mathrm{kg} \mathrm{BW}$ of $A$. vera gel showed cardioprotective activity ${ }^{16}$. Hence, doses of 100 and $300 \mathrm{mg} / \mathrm{kg} \mathrm{BW}$ of $A$. vera gel were used in the study.

\section{Study design}

Forty-eight hours after paracetamol administration, the rats were anaesthetized with intraperitoneal injection of thiopental sodium. Blood was collected via cardiac puncture and the rats were then sacrificed. The abdomen was opened and the whole liver was quickly removed and washed in ice-cold saline solution. A small section of the liver was stored at $-80^{\circ} \mathrm{C}$ for hepatic MDA and hepatic glutathione analysis. The remaining liver was fixed in $10 \%$ formalin solution for histopathology and embedded in paraffin.

\section{Assay of serum ALT and AST}

The blood samples were allowed to coagulate at room temperature for $30 \mathrm{~min}$ and then centrifuged at $3000 \mathrm{~g}$ for $15 \mathrm{~min}$ at $4{ }^{\circ} \mathrm{C}$. The activity of serum ALT and AST were measured by an automated analyser (Siemens).

\section{Estimation of hepatic MDA}

Lipid peroxidation was measured using the method in Ohkawa et al ${ }^{17}$. A $200 \mu \mathrm{l}$ aliquot of liver homogenate was added to a test tube containing $8 \%$ sodium dodecyl sulphate, $20 \%$ acetic acid, and $0.8 \%$ thiobarbituric acid. The mixture was boiled in a water bath at $95^{\circ} \mathrm{C}$ for $1 \mathrm{~h}$ and then cooled to room temperature using tap water. The mixture was centrifuged at $4000 \mathrm{~g}$ for $10 \mathrm{~min}$ at room temperature, the supernatant was then collected and the absorbance measured at $532 \mathrm{~nm}$ on a visible spectrophotometer. Hepatic MDA content was determined by comparison with a standard MDA curve and expressed as $\mathrm{nmol} / \mathrm{mg}$ protein.

\section{Determination of hepatic glutathione}

Hepatic glutathione was determined by using the Glutathione assay kit (Cayman Chemical Company). Briefly, livers were homogenized at $0{ }^{\circ} \mathrm{C}$ in phosphate buffer containing $1 \mathrm{mM}$ EDTA and centrifuged at $10000 \mathrm{~g}$ for $15 \mathrm{~min}$ at $4{ }^{\circ} \mathrm{C}$. The supernatant was collected for a hepatic glutathione assay. Hepatic glutathione was expressed as $\mathrm{nmol} / \mathrm{mg}$ protein.

\section{Histopathological examination}

Microtome sections of $5 \mu \mathrm{m}$ thickness were prepared from the formalin fixed liver according to the standard protocol and stained with haematoxylin and eosin. The histological slides were examined under light microscope by a pathologist. The extent of necrosis was graded from score $0-3$ as described previously ${ }^{18}$. Score 0 means normal liver morphology, 1 means $1-$ 2 hepatocyte rows around central vein demonstrated swelling, necrosis, 2 means extensive necrosis confined to the centrilobular region, and 3 means necrosis extending from the central zone to the midzone or further to the portal triad.

\section{Statistical analysis}

Results were expressed as the mean \pm S.E.M. for continuous data and frequency for categorical data (score of necrosis). Data were analysed using ANOVA and the Levene test was performed to evaluate the 
Table 1 Serum activities of ALT and AST enzymes in different experimental groups of rats (mean \pm S.E.M., $n=$ 6).

\begin{tabular}{lcc}
\hline Group & ALT (U/l) & AST (U/l) \\
\hline Control & $46 \pm 3$ & $97 \pm 5$ \\
Paracetamol & $860 \pm 180^{*}$ & $1400 \pm 340^{*}$ \\
A. vera $100 \mathrm{mg}$ & $2550 \pm 640^{*}$ & $3400 \pm 890^{*}$ \\
A. vera $300 \mathrm{mg}$ & $2280 \pm 700^{*}$ & $3240 \pm 100^{*}$ \\
\hline
\end{tabular}

*significantly different $(p<0.05)$ from the control

variance homogeneity. When the variances were homogeneous, Tukey's test was used to compare among all groups. If the variances were not homogeneous, the data were compared using Kruskal-Wallis and MannWhitney test. A $p$-value $<0.05$ was considered significant.

\section{RESULTS}

\section{Total phenolic contents}

The level of total phenolic contents was $4.19 \mathrm{mg}$ gallic acid equivalents per $1 \mathrm{~g}$ of $A$. vera gel powder.

\section{ALT and AST activities}

The serum activities of ALT and AST enzymes were significantly increased in the paracetamol treated group when compared with the control group. The A. vera gel treatment groups ( 100 or $300 \mathrm{mg} / \mathrm{kg} \mathrm{BW}$ ) did not show the expected decrease in the serum activities of ALT and AST as compared with the paracetamol treated group and there was no statistically difference between either the A. vera groups or the paracetamol group (Table 1).

\section{Hepatic MDA}

The level of hepatic MDA, a marker of oxidative stress, was significantly increased in the paracetamol treated group when compared with the control group. A. vera gel treatment ( 100 or $300 \mathrm{mg} / \mathrm{kg} \mathrm{BW}$ ) showed no statistically significant difference in the level of hepatic MDA compared with the paracetamol treated group (Fig. 1).

\section{Hepatic glutathione}

The level of hepatic glutathione in the control group was $2610 \pm 170 \mathrm{nmol} / \mathrm{mg}$ protein, while the paracetamol treated group was $2760 \pm 470 \mathrm{nmol} / \mathrm{mg}$ protein. In rats treated with paracetamol and A. vera gel (100 or $300 \mathrm{mg} / \mathrm{kg} \mathrm{BW}$ ), the levels of hepatic glutathione were $2880 \pm 200$ and $2240 \pm 350 \mathrm{nmol} / \mathrm{mg}$ protein, respectively. There was however was no significant difference among the groups (Fig. 2).

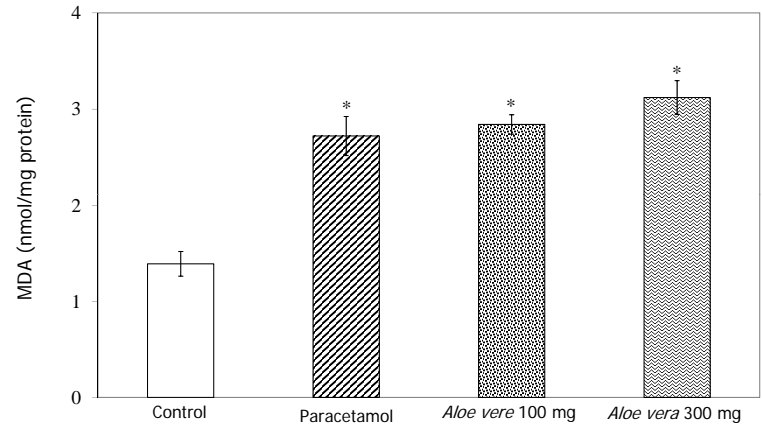

Fig. 1 Level of hepatic MDA in different experimental groups of rats (mean \pm S.E.M., $n=6$ ); * indicates a statistically significant difference $(p<0.05)$.

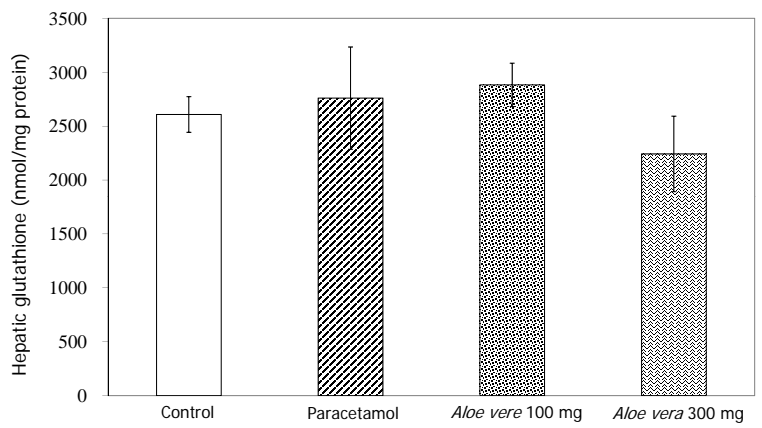

Fig. 2 Level of hepatic glutathione in different experimental groups of rats (mean \pm S.E.M., $n=6$ ).

\section{Histopathology}

The histopathological examination of liver samples in the control group showed normal liver morphology, no inflammatory-cell infiltration, or necrosis (Fig. 3a). The paracetamol treated group showed vacuolization, cell swelling, and a mild infiltration of inflammatory cells around the central vein (Fig. 3b). The necrosis was observed predominantly around both the centrilobular and midzonal regions (Fig. 3b). A. vera gel treatment (100 or $300 \mathrm{mg} / \mathrm{kg} \mathrm{BW}$ ) however did not improve liver histopathology (Fig. 3c and 3d). Centrilobular necrosis, cell swelling and vacuolar degeneration also were found in this group (Fig. $3 \mathrm{c}$ and $3 d)$. The summary of necrosis scores are shown in Table 2.

\section{DISCUSSION}

Paracetamol is widely used as an analgesic and antipyretic drug in many countries. In therapeutic does, paracetamol is primarily metabolized via sulphation and glucuronidation and then the conjugated forms are eliminated from the body. In addition, a small proportion of paracetamol is oxidized by cytochrome 

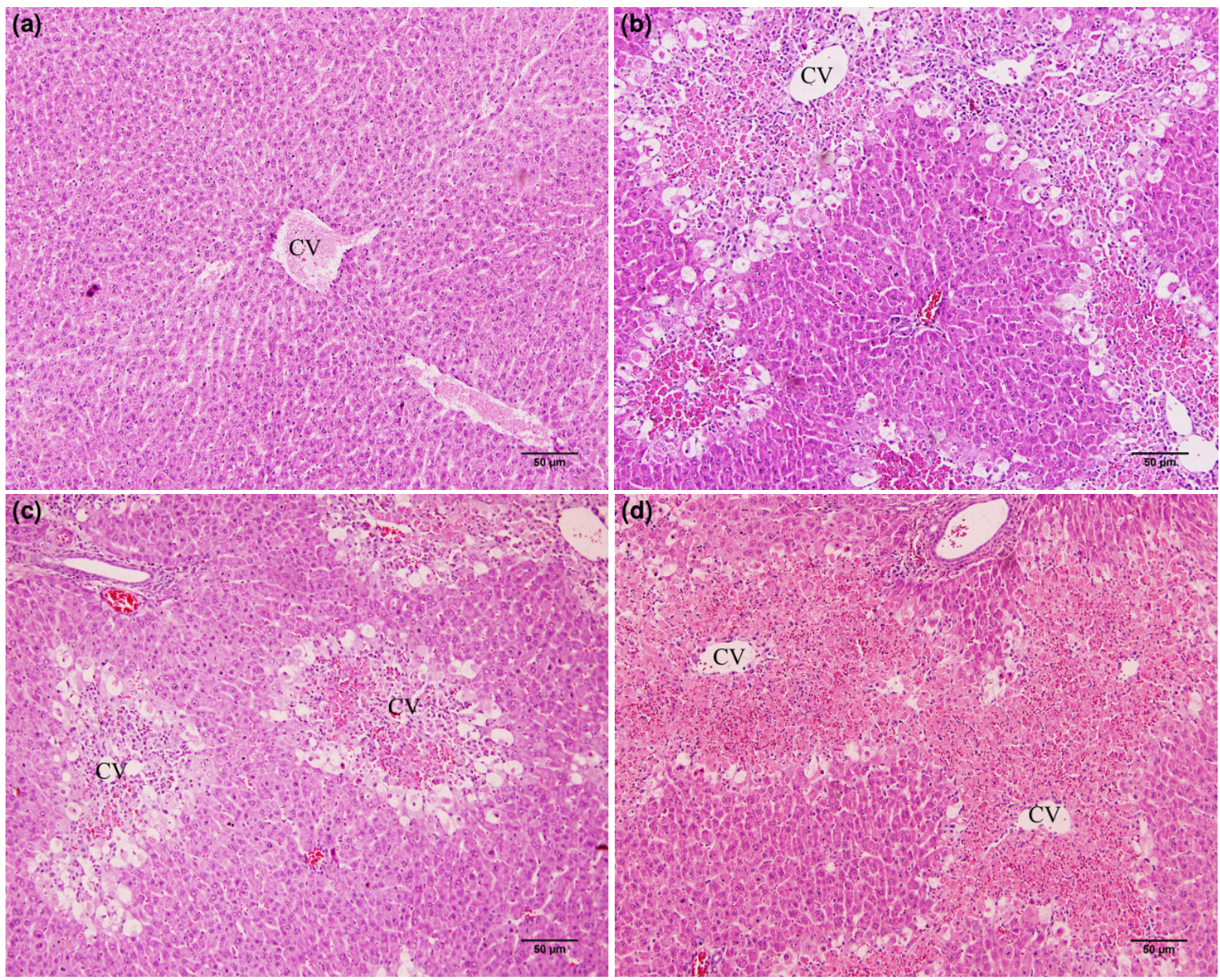

Fig. 3 Haematoxylin-eosin stained liver sections $(20 \times)$ :

(a) control group showed normal liver histopathology; (b) paracetamol treated group, (c) and (d) Aloe vera gel treatment (100 or $300 \mathrm{mg} / \mathrm{kg} \mathrm{BW}$ ) showed vacuolization, cell swelling and centrilobular necrosis. CV: central vein.

P-450 (CYP2E1, CYP1A2 and CYP3A4) to a reactive metabolite NAPQI, which is quickly detoxified by hepatic glutathione to form a nontoxic paracetamolmercaptate compound that is renally excreted. An overdose of paracetamol ingestion however generates NAPQI and depletes glutathione. When the hepatic stores of glutathione decrease to less than $30 \%$, NAPQI binds to critical proteins which disrupts normal hepatocyte function and leads to liver injury and necrosis ${ }^{19}$. Our study showed that a single dose $(2.5 \mathrm{~g} / \mathrm{kg} \mathrm{BW})$ of paracetamol administration significantly elevated the ALT and AST activity. Leakage of ALT and AST into the blood circulation is a hallmark of hepatic injury in the paracetamol model ${ }^{7,8,19}$. Furthermore, the histopathological changes such as severe centrilobular necrosis, cell swelling, and vacuolar degeneration were observed in the paracetamoltreated group. These results indicate that a single high dose $(2.5 \mathrm{~g} / \mathrm{kg} \mathrm{BW})$ of paracetamol administration can cause severe liver damage.

Apart from the primary mechanism of paracetamol toxicity, it appears that biotransformation of paracetamol via cytochrome P-450 produces free radicals (superoxide anion radicals, hydrogen peroxide, and hydroxyl radicals) leading to oxidative stress $^{5}$. Free radicals formed within cells can oxidize biomolecules such as DNA, proteins, and lipids and this may cause cell dysfunction and death. One of the characteristic features of oxidative stress is an enhanced lipid peroxidation ${ }^{20}$. The increase of hepatic MDA in the paracetamol group is consistent with previous studies ${ }^{6-8,21}$, supporting a role of oxidative stress associated with lipid peroxidation in the development of paracetamol toxicity.

Glutathione is essential for detoxification of NAPQI to a nontoxic metabolite. Several studies 
Table 2 Necrosis scores for each group $(n=6)$ expressed as the number of rats exhibiting the grade of necrosis.

\begin{tabular}{lllll}
\hline Group & \multicolumn{4}{c}{ Necrosis score } \\
\cline { 2 - 5 } & 0 & 1 & 2 & 3 \\
\hline Control & 6 & - & - & - \\
Paracetamol & - & - & 1 & 5 \\
A. vera $100 \mathrm{mg}$ & - & - & 1 & 5 \\
A. vera $300 \mathrm{mg}$ & - & - & 1 & 5 \\
\hline
\end{tabular}

Histopathology scores of necrosis: Score 0, normal liver morphology; Score 1, some of 1-2 hepatocyte rows around central vein demonstrated swelling or necrosis; Score 2, extensive necrosis confined to the centrilobular region; and Score 3, necrosis extending from the central zone to the midzone or further to the portal triad.

on the paracetamol model show paracetamol induced hepatic glutathione depletion ${ }^{7,19,21,22}$. Some studies, measurement the hepatic glutathione levels at $48 \mathrm{~h}$ after paracetamol administration found a decrease hepatic glutathione levels ${ }^{21,22}$. Hence, we evaluated hepatic glutathione levels at $48 \mathrm{~h}$. Th finding however indicates that hepatic glutathione levels did not decrease in the paracetamol-treated group. This study could be explained by a dynamic state of glutathione during paracetamol metabolism. Vendemiale et al observed the effects of paracetamol administration on hepatic glutathione content in rats and noted that the maximum hepatic glutathione depletion occurred $4 \mathrm{~h}$ after paracetamol administration, started to recover after $6 \mathrm{~h}$, and at $24 \mathrm{~h}$, had risen to approximately $73 \%$ of the basal value ${ }^{23}$. Similarly, another study showed that glutathione levels were diminished in paracetamol treated mice at 2 and $4 \mathrm{~h}$ with signs of recovery at $6 \mathrm{~h}^{24}$. It is not surprising therefore that the hepatic glutathione level did not change in the paracetamol treated group.

A. vera has therapeutic properties such as antiinflammatory, wound healing, anti-diabetic, and antioxidant effects ${ }^{10-14}$. The present study however demonstrates that $A$. vera gel treatment (100 or $300 \mathrm{mg} / \mathrm{kg} \mathrm{BW}$ ) did not decrease the liver enzyme levels, hepatic MDA levels, or improve liver histopathology in paracetamol-induced liver injury. This result may be due to differences in experimental models, dose of paracetamol, or duration of the A. vera gel treatment compared to other studies. For this reason, A. vera gel treatment, which exhibited a low total phenolic content $(4.19 \mathrm{mg}$ gallic acid equivalents per $1 \mathrm{~g}$ ), could not protect liver injury.

A. vera gel has been reported as safe to the liver. Subacute toxicity study $(300 \mathrm{mg} / \mathrm{kg}$ BW of
A. vera) showed the normal ALT and AST activities ${ }^{25}$. The $\mathrm{LD}_{50}$ of $A$. vera gel was found to be $4.8 \mathrm{~g}^{16}$. Some studies however have reported toxic effects of A. vera gel ${ }^{15,26}$. A. vera gel treatment increased the $\gamma$-glutamyl transferase in mice ${ }^{15}$. A low molecular weight fraction form $A$. vera gel exerted cytotoxic effects in vitro study ${ }^{26}$. A. vera contains quinones that react with protein thiol groups, and one should be aware of the possibility of adverse effects ${ }^{26}$.

In conclusion, 100 or $300 \mathrm{mg} / \mathrm{kg} \mathrm{BW}$ of $A$. vera gel treatment was not found to be hepatoprotective in paracetamol treated rats. The result of this study warrants additional examination of the effect of A. vera gel treatment before, during, and after paracetamol administration.

Acknowledgements: This study was financially supported by the Institute of Research and Development, Walailak University.

\section{REFERENCES}

1. Brunton L, Chabner BA, Knollmann BC (2011) Goodman \& Gilman's The Pharmacological Basis of Therapeutics, 12th edn, The McGraw-Hill Companies, New York.

2. Larson AM, Polson J, Fontana RJ, Davern TJ, Lalani E, Hynan LS, Reisch JS, Schiodt FV, et al (2005) Acetaminophen-induced acute liver failure: results of a United States multicenter, prospective study. Нераtology 42, 1364-72.

3. Wei G, Berguist A, Broome U, Lindgren S, Wallerstedt S, Almer S, Sangfelt P, Danielsson A, et al (2007) Acute liver failure in Sweden: etiology and outcome. J Intern Med 262, 393-401.

4. Craig DGN, Bates CM, Davidson JS, Martin KG, Hayes PC, Simpson KJ (2011) Pattern and outcome in paracetamol-induced acute severe hepatotoxicity. $\mathrm{Br} J$ Clin Pharmacol 71, 273-83.

5. James LP, Mayeux PR, Hinson JA (2003) Acetaminophen-induced hepatotoxicity. Drug Metabol Dispos 31, 1499-506.

6. Kheradpezhouh E, Panjehshahin MR, Miri R, Javidnia K, Noorafshan A, Monabati A, Dehpour AR (2010) Curcumin protects rats against acetaminophen-induced hepatorenal damages and shows synergistic activity with N-acetyl cysteine. Eur J Pharmacol 628, 274-81.

7. Samanawat K, Thong-Ngam D, Klaikeaw N (2012) Effects of curcumin attenuated hepatitis in mice with paracetamol overdose. Thai J Gastroenterol 13, 43-9.

8. Olaleye MT, Rocha JBT (2008) Acetaminophen-induced liver damage in mice: effects of some medicinal plants on the oxidative defense system. Exp Toxicol Pathol 59, 319-27.

9. Hamman JH (2008) Composition and applications of Aloe vera leaf gel. Molecules 13, 1599-616. 
10. Suvitayavat W, Sumrongkit C, Thirawarapan SS, Bunyapraphatsara N (2004) Effects of Aloe preparation on the histamine-induced gastric secretion in rats. J Ethnopharmacol 90, 239-47.

11. Rajasekaran S, Sivagnanam K, Subramanian S (2005) Antioxidant effect of Aloe vera gel extract in streptozotocin-induced diabetes in rats. Pharmacol Rep 57, 90-6.

12. Oryan A, Naeini AT, Nikahval B, Gorjian E (2010) Effect of aqueous extract of Aloe vera on experimental cutaneous wound healing rat. Vet Arhiv 80, 509-22.

13. $\mathrm{Hu} \mathrm{Y,} \mathrm{Xu} \mathrm{J,} \mathrm{Hu} \mathrm{Q} \mathrm{(2003)} \mathrm{Evaluation} \mathrm{of} \mathrm{antioxidant} \mathrm{po-}$ tential of Aloe vera (Aloe barbadensis Miller) extracts. J Agr Food Chem 51, 7788-91.

14. Chandan BK, Saxena AK, Shukla S, Sharma N, Gupta DK, Suri KA, Suri J, Bhadauria M, Singh B (2007) Hepatoprotective potential of Aloe barbadensis Mill. against carbon tetrachloride induced hepatotoxicity. J Ethnopharmacol 111, 560-6.

15. Gbadegesin MA, Odunola OA, Akinwumi KA, Osifeso OO (2009) Comparative hepatotoxicity and clastogenicity of sodium arsenite and three petroleum products in experimental Swiss Albino Mice: the modulatory effects of Aloe vera gel. Food Chem Toxicol 47, 2454-7.

16. Kaithwas G, Dubey K, Pillai KK (2011) Effect of Aloe vera (Aloe barbadensis Miller) gell on doxorubicininduced myocardial oxidative stress and calcium overload in albino rats. Indian J Exp Biol 49, 260-8.

17. Choi Y, Lee SM, Chun J, Lee HB, Lee J (2006) Influence of heat treatment on the antioxidant activities and polyphenolic compounds of Shiitake (Lentinus edodes) mushroom. Food Chem 99, 381-7.

18. Ohkawa H, Ohishi N, Yagi K (1979) Assay for lipid peroxides in animal tissues by thiobarbituric acid reaction. Anal Biochem 95, 351-8.

19. Wongnawa $M$, Thaina $P$, Bumrungwong N, Rattanapirun P, Nitiruangjaras A, Muso A, Prasartthong $\mathrm{V}$ (2006) The protective potential and possible mechanism of Phyllanthus amarus Schum. \& Thonn. aqueous extract on paracetamol-induced hepatotoxicity in rats. Songklanakarin J Sci Tech 28, 551-61.

20. de Zwart LL, Meerman JHN, Commandeur JNM, Vermeulen NPE (1999) Biomarkers of free radical damage: applications in experimental animals and in humans. Free Radic Biol Med 26, 202-26.

21. Abdel-Zaher AO, Abdel-Hady RH, Mahmoud MM, Farrag MMY (2008) The potential protective role of alpha-lipoic acid against acetaminophen-induced hepatic and renal damage. Toxicology 243, 261-70.

22. Ramachandra Setty S, Quereshi AA, Viswanath Swamy AHM, Patil T, Prakash T, Prabhu K, Veeran Gouda A (2007) Hepatoprotective activity of Calotropis procera flowers against paracetamolinduced hepatic injury in rats. Fitoterapia 78, 451-4.

23. Vendemiale G, Grattagliano I, Altomare E, Turturro N, Guerrieri F (1996) Effect of acetaminophen administration on hepatic glutathione compartmentation and mitochondrial energy metabolism in the rat. Biochem Pharmacol 52, 1147-54.

24. Rogers LK, Valentine CJ, Szczpyka M, Smith CV (2000) Effects of hepatotoxic doses of acetaminophen and furosemide on tissue concentrations of CoASH and CoASSG in vivo. Chem Res Toxicol 13, 873-82.

25. Ghosh AK, Banerjee M, Mandal TK, Mishra A, Bhowmik MK (2011) A study on analgesic efficacy and adverse effects of Aloe vera in Wistar rats. Pharmacologyonline 2011-1, 1098-108.

26. Avila H, Rivero J, Herrera F, Fraile G (1997) Cytotoxicity of a low molecular weight fraction from Aloe vera (Aloe barbadensis Miller) gel. Toxicon 35, 1423-30. 